ESTUDOS R:EP

\title{
Um quinquênio de cotas: as chances de ingresso de negros na Universidade de Brasília
}

Jacques Velloso

Claudete Batista Cardoso

\section{Resumo}

No contexto dos debates sobre as ações afirmativas no ensino superior, o estudo tratou de cotas para negros na Universidade de Brasília (UnB), valendo-se de escores dos candidatos ao vestibular no quinquênio 2004-2008. Duas questões centrais orientaram o estudo: Quais seriam as chances de ingresso de candidatos negros, caso inexistisse o sistema de cotas? Essas chances aumentariam expressivamente caso as vagas oferecidas pela instituição fossem duplicadas? Para responder às perguntas foram feitas simulações das chances de ingresso de negros. As cotas em geral dobraram as chances de aprovação de candidatos negros na UnB, mas os resultados não sustentaram a tese de que um forte aumento nas vagas poderia substituir as cotas e, ao mesmo tempo, sinalizaram para a relevância de políticas universalistas voltadas para a educação básica.

Palavras-chave: ações afirmativas; sistema de cotas; chances de ingresso; educação superior; Universidade de Brasília. 


\section{Abstract \\ Quotas in five years' time: admission chances of blacks at the University of Brasilia}

In the context of the debate on affirmative action in higher education, the study dealt with quotas for blacks in the University of Brasilia (UnB), using scores obtained by applicants in entrance examinations in a five year period (2004-2008). The two main questions of the study were: What would be the admission chances of black applicants, if the quota system did not exist? If admission slots were doubled, would these chances undergo a substantial increase? In order to answer these questions, admission chances were simulated. Data indicated admission chances of black applicants typically are twice as large under the quota system. Results did not support the argument that a large expansion of admission slots could replace the quota system and, at the same time, pointed out to the relevance of universalist policies aimed at basic schooling.

Keywords: affirmative action; admission chances; higher education; University of Brasília; quota system.

\section{Introdução}

O sistema educacional brasileiro, refletindo a sociedade na qual ele opera, discrimina pela cor da pele. Pretos e pardos têm menores chances de acesso à escola, de progresso no sistema educacional e de ingressar no ensino superior, quando comparados a brancos. Nesse quadro, na esteira da Conferência da ONU em Durban sobre Racismo, Discriminação Racial, Xenofobia e Intolerância Correlata, em 2001, e de propostas e reivindicações do Movimento Negro (Silva, 2003), que entre outras finalidades buscavam aumentar o contingente de pretos e pardos na educação superior (Munanga, 2003), desde a década passada diversas universidades brasileiras vêm adotando políticas de ações afirmativas, com reserva de vagas para negros, ou para estes no interior de cotas para estudantes oriundos da escola pública.

As políticas de cotas nas universidades vêm sendo objeto de intenso debate. Na crítica a essas políticas, as cotas representariam uma ruptura com a ideologia que define o Brasil como país da mistura, conduzindo a uma bipolarização racial e a uma ampliação da tensão inter-racial (Fry, Maggie, 2005, p. 306-307), e cuja implantação implicaria um país de duas raças, rejeitando a mestiçagem e a democracia racial como valores positivos, podendo até aumentar o racismo na sociedade (Fry, Maggie, 2004). 
Esse debate baseia-se, entre outros aspectos, na conexão entre desigualdades raciais, educacionais e de renda, desde há tempos evidenciada em vários estudos. No ano do centenário da abolição, em 1988, pretos e pardos com renda até um quarto do salário mínimo representavam 44\% da população do País, mas constituíam 65\% dos pobres com esse nível de rendimentos, concentrando-se em bolsões de pobreza, como no Nordeste e em periferias de regiões metropolitanas (Hasenbalg, 1997, com base em dados de Silva, 1992). Aquela conexão se desdobrava em outras relações, como nas escolares: crianças não brancas alcançavam menos anos de estudo que as brancas; cerca de metade daquelas não conseguia ir além da $4^{\mathrm{a}}$ série do ensino fundamental, pois estereótipos dos professores sobre a educabilidade das crianças negras e pobres atuariam como profecias que se autorrealizavam, como corretamente entendia Hasenbalg (1997).

O debate continua na matriz de resultados como os mencionados, que em boa medida decorrem do desempenho diferenciado de negros e brancos no sistema educacional, o qual está associado à qualidade da educação obtida e a desigualdades de nível social.

Um estudo sobre o desempenho escolar de negros e brancos, com dados nacionais do Saeb para 2001, mostrou que havia grandes diferenças na proficiência dos alunos conforme a cor da pele, classificada em três categorias, brancos, pardos e pretos. Soares e Alves (2003) constataram que, no desempenho em Matemática na $8^{\mathrm{a}}$ série, a diferença de performance entre brancos e pardos era da ordem de $7 \%$, mas quase dobrava quando se comparavam brancos e pretos.

Outro estudo sobre o desempenho escolar, considerando desigualdades raciais e socioeconômicas, realizado com uma amostra de escolas da metrópole de Belo Horizonte, encontrou efeitos significativos da cor da pele sobre o desempenho em matemática dos alunos da $4^{\mathrm{a}}$ série do ensino fundamental, mesmo controlando-se estatisticamente os efeitos da renda familiar, da escolaridade da mãe e da qualidade da escola, conforme apurou Barbosa (2005). Mas a autora também registrou que a qualidade das escolas tinha efeitos expressivos sobre o rendimento escolar de crianças negras ou brancas, de baixo ou alto status socioeconômico, tal como na pesquisa de Soares e Alves. Conforme os resultados da autora, a qualidade da escola pode contribuir para a redução das desigualdades sociais e de cor: as escolas de boa qualidade têm possibilidades objetivas de reduzir as diferenças de desempenho entre alunos brancos e não brancos, constituindo-se num instrumento forte e eficaz de luta contra as desigualdades sociais (Barbosa, 2005, p. 114, 115). Mas até agora não tem sido esse o principal papel desempenhado pelas escolas no País.

É bem verdade que as diferenças entre negros e brancos no acesso à escola vêm se reduzindo, um pouco no ensino fundamental e bastante no ensino médio, como vêm mostrando os dados das Pnads. No entanto, como mostrou o trabalho de Bonamino, Franco e Alves (2005) com dados do Saeb, o crescimento das taxas de escolarização para negros teve como contrapartida uma perversa mudança nas relações socioeducacionais que condicionam o rendimento escolar dos jovens e influem no acesso à universidade. Os dados 
do Saeb para o desempenho em matemática revelaram, no período estudado, um aumento na diferença entre brancos e não brancos na última série do ensino médio, justamente na antessala do ensino superior. Entre 1995 e 2001, o aumento no hiato foi de quase 30\%, alargando expressivamente a distância entre os dois grupos. Quando os resultados foram ajustados pelo nível socioeconômico das famílias dos alunos, isto é, quando o efeito da raça fluiu livremente, tornando-se estatisticamente independente daquela variável, o crescimento da diferença alcançou mais de 40\%. Num e noutro caso, e mais fortemente ainda neste último, os dados sugerem que ao longo dos anos a desigualdade racial surgia sob nova roupagem, perversamente contrapondo-se à ampliação do acesso de negros à escola.

As consequências desse panorama quanto ao acesso ao ensino superior não são difíceis de imaginar. Uma delas é revelada pela produção das diferenças educacionais no acesso à educação superior, entre negros e brancos, ao longo de uma geração. Osório e Soares (2005), com dados da Pnad de 2003 para as pessoas que frequentavam algum nível do sistema educacional, estudando os nascidos em 1980, constataram que 66\% dos brancos estavam matriculados no nível superior. Enquanto isso, 70\% dos negros ainda estavam na educação básica, certamente em virtude de uma associação de variáveis que incluem condições socioeconômicas mais desfavoráveis para negros em relação a brancos, desigualdades no acesso ao sistema de ensino e ritmos diferenciados de progressão no sistema, bem como preconceito e discriminação no interior da escola. O efeito desses fatores também é evidenciado, noutro prisma, entre formandos do ensino superior que fizeram o Exame Nacional de Cursos (Provão) de 1999. Entre eles, havia nítida diferença por cor da pele entre os mais e os menos jovens. Na faixa etária de 18-24 anos, 13\% eram negros, enquanto no grupo de 25 anos e mais a proporção ascendia a 18\% (Sampaio, Limongi, Torres, 2000), seguramente reflexo das desigualdades referidas.

Mas antes da geração de 80, analisada por Osório e Soares, as diferenças eram ainda maiores. Dados dos censos demográficos elaborados por Beltrão e Teixeira (2005) indicavam que em 1960, na população com dez anos e mais, 1,4\% dos homens tinham nível superior, mas a proporção de pretos com esse grau de escolaridade era quase 50 vezes menor, uma distância abismal; para pardos a diferença era menos gritante, mas mesmo assim extraordinária: a fração destes era cerca de dez vezes menor que a dos brancos. Ao longo de décadas, com a expansão da educação básica e sobretudo no ensino superior, as diferenças foram caindo e beneficiando principalmente os pretos. Quarenta anos mais tarde, em 2000, a porcentagem de brancos com nível superior era cinco vezes maior que a de pretos (e também de pardos) - ainda uma formidável diferença, conquanto muito inferior à de antes. Mais ou menos na mesma época, dados ilustrativos para seis universidades públicas em distintas regiões do País se coadunavam com o cenário apurado por Beltrão e Teixeira no censo de 2000. Em cada uma dessas instituições, eram bem expressivas as diferenças entre as parcelas de alunos negros e a porcentagem de negros nos respectivos estados, sendo a menor na Universidade Federal do Paraná 
(UFPR) e a maior na Universidade Federal da Bahia (UFBA), conforme dados de Guimarães (2003).

Na virada do século, o hiato de escolaridade entre negros e brancos havia sofrido um forte estreitamento, iniciado há algumas décadas mediante alargamento de oportunidades educacionais, no qual negros se beneficiaram mais que brancos. Entretanto, a distância permanecia imensa - e o ritmo da redução não prenunciava uma efetiva aproximação das chances de acesso e de conclusão da educação superior num horizonte imediatamente visível.

As desigualdades discutidas, embora importantes, não revelam outras de relevância similar, que dizem respeito às carreiras em que ingressam negros e àquelas que acolhem brancos, conforme evidência também apresentada por Beltrão e Teixeira (2005), com os mesmos dados do censo de 2000. Entre profissionais de nível superior, as proporções de brancos tendem a crescer à medida que aumenta o prestígio social das carreiras (e, naturalmente, o padrão de remuneração), ocorrendo o inverso com negros. Em carreiras como Serviço Social, Enfermagem e Letras, a presença de negros geralmente é maior que em outras, como Arquitetura, Direito, Engenharia Mecânica e Medicina, nas quais brancos costumam ter ampla predominância.

Foi nesse contexto de desigualdades raciais e socioeducacionais esboçadas que, em 2004, no âmbito dos debates sobre ações afirmativas na Universidade de Brasília (UnB), a instituição adotou um sistema de cotas. Neste, 20\% das vagas de cada curso passaram a ser reservadas para candidatos negros (cotistas); os outros candidatos continuaram a concorrer pelo vestibular tradicional, que passou a se chamar sistema universal. No presente estudo, interessa-nos identificar efeitos do sistema de cotas sobre as oportunidades de acesso de negros à UnB em cinco vestibulares - de 2004 a 2008. Noutros termos, buscamos saber quais seriam as chances de ingresso dos candidatos que se inscreveram pelo sistema de reserva de vagas caso este não tivesse sido adotado. Num segundo momento, consideramos um dos argumentos contrários às cotas raciais, no sentido de que estas deveriam ser substituídas por uma vigorosa expansão das vagas na educação superior. Desejamos então saber, de modo análogo ao objetivo anterior, quais seriam as probabilidades de entrada dos candidatos negros caso o sistema de cotas não tivesse sido adotado, porém, agora, supondo que as vagas ofertadas pela UnB correspondessem ao dobro das que foram efetivamente oferecidas a cada ano. Na próxima seção discutimos os procedimentos metodológicos adotados. Na seguinte analisamos os resultados obtidos por grupos de cursos das áreas do conhecimento do vestibular da UnB (Humanidades, Ciências e Saúde), concluindo com uma nota final.

\section{Metodologia}

A concepção original da pesquisa pretendia comparar cotistas e não cotistas de extração social semelhante, em virtude da conhecida influência 
de variáveis socioeconômicas sobre o desempenho no vestibular. Para tanto contávamos com dados de questionários que seriam respondidos por ocasião da inscrição para o vestibular na UnB. Entre os candidatos cotistas, que precisavam ser fotografados in loco na universidade, a taxa de resposta na seleção de 2004 alcançou o excelente nível de mais de 90\%, mas, como o preenchimento não era obrigatório, caía para 80\% no ano seguinte e continuava sua trajetória descendente nos demais anos. Entre os candidatos do sistema universal, em 2004 a taxa já era muito baixa, em torno de 50\%, diminuindo mais ainda nos anos seguintes e inviabilizando as comparações pretendidas. No presente estudo, como um substituto das pretendidas variáveis socioeconômicas, utilizamos um agrupamento de cursos em duas categorias de prestígio, maior e menor, para cada uma das três áreas do conhecimento do vestibular da UnB, resultando num total de seis categorias. O prestígio social dos cursos costuma estar associado ao nível socioeconômico de seus alunos, como revela a literatura sobre o tema (Braga, Peixoto, Bogutchi, 2001). As categorias assim definidas serviram, portanto, como proxy do nível socioeconômico dos candidatos.

Na área das Humanidades, o grupo de maior prestígio social abrangeu cursos como Administração, Arquitetura, Direito, Comunicação Social; no grupo dos menos valorizados, Contabilidade, Filosofia, Letras e Pedagogia, entre outros. Na área de Ciências, no grupo dos mais concorridos, carreiras ilustrativas são Biologia, Computação, Engenharia Mecatrônica, Física (Física Computacional); no grupo das menos valorizadas, Agronomia, Geologia, Licenciaturas em Física e em Matemática. Na área da Saúde, no grupo de maior prestígio situaram-se Medicina, Farmácia e Odontologia e, no de prestígio social relativamente menor, carreiras como Enfermagem, Educação Física e Nutrição - em Cardoso (2008) e em Velloso (2009) encontram-se pormenores da construção e composição dos grupos.

As populações do estudo são as cinco coortes de candidatos aos vestibulares para ingresso na UnB no segundo semestre letivo de 2004 a 2008, inscritos nos dois sistemas de ingresso (universal e cotas) para os cursos oferecidos no campus sede da UnB (Campus Darcy Ribeiro) e que estiveram presentes às provas. A fim de que os dados fossem comparáveis ao longo de todo o período estudado, foram excluídos os candidatos a cursos dos três novos campi da universidade, Planaltina, Ceilândia e Gama, o primeiro deles implantado em 2006 e os outros dois em 2008. As populações estão apresentadas na Tabela A-1 do apêndice.

Até 2007, a homologação da inscrição de um candidato cotista era realizada por uma comissão que analisava a fotografia e os dados do pretendente em processo que tem sido objeto de acertadas críticas, como a de um dos autores da proposta do sistema de cotas da UnB, Carvalho (2005), que via um sentido político na autodeclaração de negro (em vez de preto ou pardo), por isso dispensando qualquer certificação posterior, ou como a de Maio e Santos (2005), insinuando que na classificação racial da comissão havia ares da superada e repudiada antropologia física que se praticava no final do século 19 e no início do século 20, cerca de cem 
anos antes da implantação das cotas na UnB. A partir de 2008 a UnB suprimiu a exigência de foto, mas passou a requerer uma entrevista (realizada depois do vestibular) para homologar a inscrição no sistema de reserva de vagas, à moda da UFPR. Nesta, a confirmação da vaga de candidato aprovado nas cotas para negros é feita há tempos por comissão destinada a verificar se o candidato possui "traços fenotípicos que o identificam com o tipo negro, objeto da discriminação racial existente no Brasil" (Bevilaqua, 2005, p. 27). Na UnB, até 2007, os candidatos cotistas concorriam inicialmente pela reserva de vagas e, caso não fossem aprovados nesta modalidade, passavam a competir pelo sistema universal. A partir de 2008, os candidatos que pretendiam concorrer pela reserva de vagas não mais concorreriam, concomitantemente, pelo sistema universal.

No intuito de conhecer os efeitos do sistema de cotas, foram efetuados dois tipos de simulação das chances de ingresso de candidatos negros para cada um dos vestibulares do quinquênio analisado. No primeiro tipo considerou-se o número de vagas efetivamente ofertado pela UnB em cada curso/turno. Todos os candidatos, tanto os do sistema universal quanto o do sistema de cotas, foram então ordenados em cada curso/turno conforme seus argumentos finais no vestibular, do maior para o menor, sem distinção de sistema de ingresso. Foram tidos como aprovados os " $n$ " primeiro colocados, conforme o número " $\mathrm{n}$ " de vagas em cada curso/turno. No curso de Engenharia Elétrica em 2004, por exemplo, que ofereceu 40 vagas, foram tidos como aprovados os 40 primeiros colocados, independentemente do tipo de sistema de ingresso em que se inscreveram os vestibulandos. No segundo tipo de simulação considerou-se a hipótese de que a UnB teria oferecido, em cada curso/turno, o dobro das vagas efetivamente ofertadas. Repetiram-se então os procedimentos antes descritos, porém agora considerando o dobro de vagas.

\section{Chances de ingresso dos cotistas: simulações}

Quais seriam as chances de ingresso na UnB para os cotistas caso o sistema de cotas não tivesse sido implantado? Essas probabilidades se alterariam caso houvesse um vigoroso aumento nas vagas? As respostas a essas perguntas foram dadas por dois tipos de simulações. Apresentam-se inicialmente os resultados das simulações do primeiro tipo (vagas originais) e, mais adiante, os do segundo tipo (vagas dobradas).

\section{Simulações com vagas originais: principais tendências}

Comecemos a discussão das simulações com as vagas efetivamente oferecidas na área de Humanidades. Na seleção de 2004, se o sistema de cotas não existisse no vestibular daquele ano, somente $11 \%$ das vagas em cada curso dessa área seriam ocupadas por candidatos negros, ou seja, o equivalente a quase metade da reserva para cotistas (Gráfico 1.a). 
Nesse ano, as duas vias de entrada então instituídas revelavam-se um poderoso instrumento de ampliação das oportunidades de acesso dos candidatos negros aos cursos das Humanidades: as cotas quase que duplicavam suas chances de aprovação na UnB. Nas carreiras de maior prestígio, as chances seriam de $8 \%$, e o sistema de cotas mais que as dobrou; nesse grupo, nos cursos de Arquitetura e de Economia, casos extremos, nenhum vestibulando negro entraria sem a reserva de vagas. O quadro é distinto em cursos de menor prestígio social dessa área, como Serviço Social e Pedagogia, nos quais todos ou quase todos os cotistas dispensariam a reserva de vagas para a aprovação na universidade. Nestes dois, a reserva de vagas teve efeito nulo ou quase nulo.

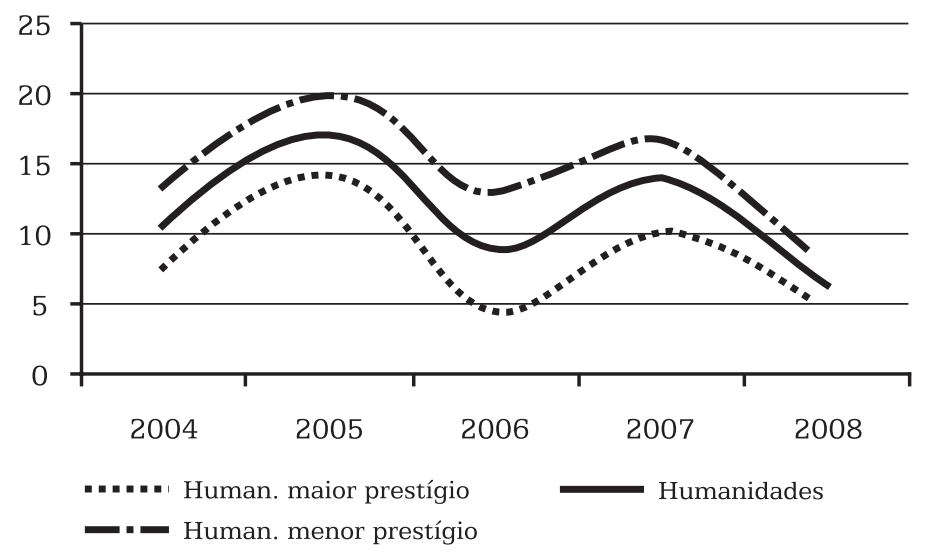

\section{Gráfico 1.a - Humanidades: simulações da aprovação de candidatos negros em cinco hipotéticos vestibulares da UnB, sem cotas, com o número de vagas real (\%)}

Fonte: Microdados do Cespe/UnB; elaboração dos autores.

Em 2005, as chances de ingresso cresceram muito e, com isso, a relevância da reserva de vagas nas Humanidades se alterou abruptamente, como mostra o Gráfico 1.a. Se o sistema de cotas não existisse no vestibular de 2005, 17\% das vagas nessa área seriam ocupadas por candidatos negros, porcentagem praticamente idêntica à participação destes no total de inscritos e bem próxima da reserva de $20 \%$ das vagas. Na área das Humanidades, os efeitos das cotas foram bem mais modestos nesse ano. No conjunto dos cursos menos concorridos das Humanidades, esses efeitos foram nulos, pois o índice simulado de aprovação de negros foi igual à proporção das cotas, $20 \%$ das vagas. Na verdade, em alguns cursos, como Pedagogia e Serviço Social, os candidatos que concorreram pelo sistema de cotas ocupariam - como efetivamente ocuparam - parte das vagas oferecidas aos inscritos no sistema universal. Nesses dois cursos, 26\% e $33 \%$ dos aprovados eram negros, respectivamente, e seriam aprovados caso inexistissem as cotas.

Qual a origem dessa expressiva diferença nas chances de aprovação no biênio? Examinando mais a fundo os dados da pesquisa, constatamos que o perfil socioeconômico dos candidatos da reserva de vagas das 
Humanidades sofreu formidável deslocamento para cima, entre as coortes de 2004 e 2005: a proporção desses candidatos cujas mães têm nível superior, por exemplo, mais que dobrou. Com esse deslocamento, os perfis sociais de cotistas e não cotistas teriam se aproximado. Considerando a influência do nível socioeconômico sobre o desempenho no vestibular, como evidenciado, por exemplo, em Dias et al. (2008) e Valle et al. (2010), a elevação do perfil social dos cotistas da coorte de 2005 contribuiria então para explicar o aumento de suas chances de acesso à UnB em relação a seus colegas da coorte de 2004 .

De outra parte, os dados ainda sugeriram que de 2004 para 2005, entre os candidatos do sistema universal, também poderia ter ocorrido uma elevação de seu perfil social. De fato, outra pesquisa, contando com informações coligidas em survey conduzido pelos autores junto a uma amostra de estudantes da UnB, indicou que, efetivamente, o perfil social de cotistas e não cotistas deslocou-se para cima em 2005 (Francis, TannuriPianto, 2010). Esses resultados implicariam descartar a hipótese de que a mudança no nível socioeconômico dos cotistas em 2005 teria sido um dos fatores responsáveis pela melhoria de seu desempenho no vestibular daquele ano.

A rejeição dessa hipótese, entretanto, se baseia na suposição de efeitos lineares da condição socioeconômica sobre o desempenho na seleção. Mas a análise de Diaz (2007, p. 117) com dados do Provão de 2000 encontrou um "padrão não linear no impacto da renda familiar sobre o rendimento dos alunos" de Administração, Direito e Engenharia Civil. Em seus dados, o rendimento dos formandos da faixa intermediária de renda (de 10 a 20 salários mínimos) não diferiu do obtido pelos estudantes da mais alta faixa de renda; estes, por sua vez, tiveram média menor que os formandos da faixa de renda imediatamente anterior. É bem possível que, no presente estudo, efeitos não lineares como esses tenham atuado no desempenho de cotistas nos vestibulares de 2004 e 2005. Nesse sentido, admitamos que os candidatos cotistas e não cotistas de 2005 tenham sofrido um deslocamento para cima em seus perfis sociais, comparativamente aos do ano anterior. Como os candidatos do universal na seleção de 2004 já possuiriam uma condição socioeconômica privilegiada em relação aos cotistas, o aparente deslocamento em 2005 os teria situado num patamar no qual variações na extração social exerceriam efeitos muito pequenos ou mesmo nulos sobre o desempenho. Para os cotistas, ao contrário, o deslocamento em 2005 teria tido efeitos positivos sobre o desempenho na seleção. Nesse cenário, a elevação do perfil social dos cotistas seria em larga medida responsável pelo melhor desempenho no vestibular de 2005 e, consequentemente, pelo menor efeito das cotas nessa seleção.

A partir de 2006 também houve expressivas variações nas chances de ingresso dos candidatos negros. Depois do grande aumento de 2005, no ano subsequente esse índice caiu quase à metade, pois, no conjunto dos cursos das Humanidades, 9\% das vagas seriam ocupadas por negros caso o sistema de cotas inexistisse (Gráfico 1.a). Nos dois vestibulares 
ulteriores, o índice inicialmente volta a subir, mas cai muito no ano seguinte: em 2007 alcançou 14\% e, em 2008, somente 6\%. Nos cincos anos analisados no presente estudo, foi em 2008 que o sistema de reservas de vagas teve o maior efeito. Para além dessas variações, o Gráfico 1.a também mostra que, ao longo do quinquênio estudado, as chances de entrada na UnB seriam menores nos cursos de maior prestígio social. Adiante discutiremos essa tendência.

A forte queda nas chances de ingresso dos candidatos negros no vestibular de 2008, comparativamente ao de 2007, possivelmente está associada à mudança que foi introduzida nas normas para homologação da inscrição dos candidatos às cotas. Até 2007, o julgamento do pedido de inscrição na reserva de vagas era feito antes da realização do vestibular, mediante exame da fotografia do pretendente, como mencionamos anteriormente. Se o pedido de inscrição não fosse homologado, o candidato concorreria pelo sistema universal. A partir de 2008 ocorreu uma profunda mudança no sistema de cotas. O julgamento do pedido de inscrição na reserva de vagas passou a ser feito depois de realizado o vestibular, mediante entrevista com uma banca. ${ }^{1}$ Se o pleito de inscrição como cotista fosse rejeitado, o candidato era alijado do vestibular: ele não mais concorreria pelo sistema universal nem, evidentemente, como cotista. É provável que a mudança de 2008 tenha afastado candidatos que se inscreveriam na reserva de vagas caso a sistemática anterior ainda estivesse em vigor. Se a maioria desses candidatos possuísse preparo para o vestibular superior ao de seus colegas que se inscreveram como cotistas, e que tiveram sua inscrição homologada, estaria então explicada, em larga medida, a queda das chances de aprovação dos candidatos negros em 2008. A hipótese é mais bem especulativa, pois lhe faltam elementos que possam torná-la suficientemente plausível. Futuros estudos com dados dos vestibulares de 2009 em diante, todos na vigência da nova sistemática das cotas, talvez lancem luz sobre as indagações que hoje ainda se encontram sem resposta.

Passemos agora ao exame das probabilidades de entrada de candidatos negros nos cursos da área de Ciências (Gráfico 1.b). Nessa área, em 2004, os candidatos negros se beneficiaram mais da reserva de vagas que seus colegas das Humanidades (e da Saúde, como veremos adiante); suas chances de aprovação nas Ciências seriam de 6\%, e, assim, as cotas mais que triplicaram essas probabilidades. Nos cursos de maior prestígio, tal como nas Humanidades, as cotas produziram seu efeito mais forte. Nesse grupo, o duplo sistema de ingresso aumentou em quatro vezes as chances de aprovação de negros; em alguns cursos do grupo, como Engenharia Civil, nenhum cotista ingressaria sem a reserva de vagas.

Fenômeno análogo ao constatado nas Humanidades em 2005, de deslocamento para cima do perfil social dos cotistas, também ocorreu nos cursos das Ciências, aumentando as taxas simuladas de aprovação dos candidatos negros. Nessa área, as taxas em 2005 variaram de 11\% a 16\% das vagas. Com esses elevados níveis de hipotética aprovação nas Ciências em 2005, e ao contrário do ano anterior, nas simulações realizadas houve
${ }^{1} \mathrm{O}$ número de candidatos convocados para a banca é aproximadamente o dobro da quantidade de vagas reservadas para cotistas. 
candidatos negros aprovados em todos os cursos. A situação de dois cursos das Engenharias é muito ilustrativa da profunda diferença operada nas chances de aprovação entre os dois vestibulares. Nos cursos de Engenharia Florestal e de Engenharia de Redes de Comunicação, o primeiro do grupo de cursos menos valorizados e o segundo do grupo de mais concorridos, nenhum candidato negro ingressaria em 2004 se inexistissem as cotas. Já em 2005 os índices simulados de aprovação nesses dois cursos eram de $10 \%$ e $15 \%$ das vagas, respectivamente.

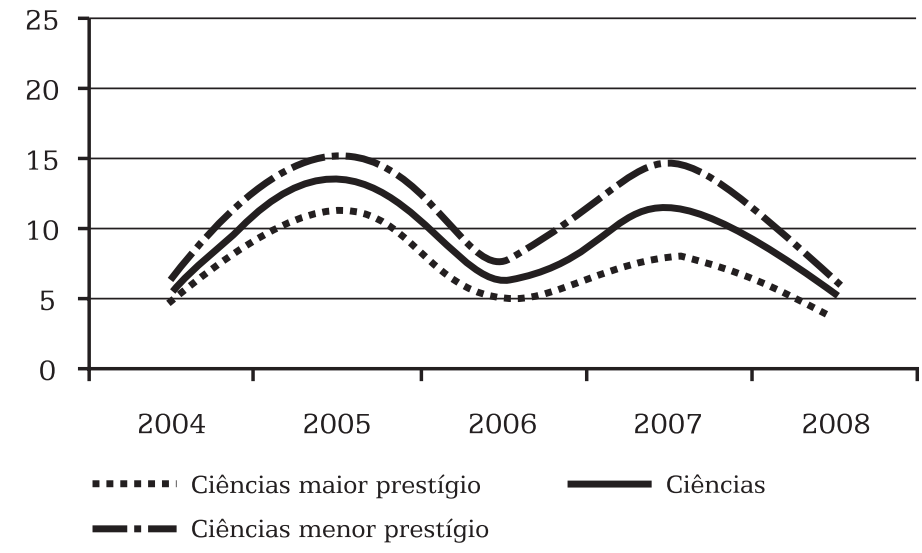

\section{Gráfico 1.b - Ciências: simulações da aprovação de candidatos negros em cinco hipotéticos vestibulares da UnB, sem cotas, com o número de vagas real (\%)}

Fonte: Microdados do Cespe/UnB; elaboração dos autores.

Em 2006, de modo semelhante ao que ocorreu nas Humanidades, as chances de ingresso de negros nas Ciências também diminuiriam muito, para $7 \%$, equivalentes à metade das probabilidades de um ano antes. Nos dois anos seguintes, e ainda em ritmo parecido ao das Humanidades, as taxas simuladas de aprovação inicialmente subiram muito (2007), quase que dobrando em relação ao ano anterior, e depois também caíram para o menor nível do período, 5\% (2008). Além dessas variações, também podemos constatar no Gráfico 1.b que os índices simulados dos dois grupos de cursos, ao longo do quinquênio, tiveram comportamento semelhante ao padrão observado nas Humanidades, com magnitude inversamente proporcional ao nível de prestígio social de carreiras. Adiante trataremos dessa tendência.

Na Saúde, os efeitos das cotas geralmente se situaram num plano intermediário entre os registrados para as outras duas áreas (Gráfico 1.c). Em 2004, no conjunto da área, as cotas mais que dobraram as probabilidades de ingresso de negros; como nas demais áreas, os efeitos das cotas foram mais intensos nos cursos de maior prestígio. Na seleção de 2005, o perfil social dos candidatos negros deslocou-se para cima, de modo análogo ao ocorrido nas Humanidades e nas Ciências, e com ele subiram as taxas simuladas de aprovação, que alcançaram magnitudes parecidas à das Ciências naquele ano. 
Nas simulações referentes a 2006 para a área de Saúde, ao contrário do que ocorreu nas outras duas áreas, os índices de entrada de negros não se distanciaram tanto dos observados no ano anterior. Ademais, os grupos de cursos exibiram um comportamento peculiar, no qual os índices foram maiores nas carreiras mais valorizadas. Efetivamente, em cursos como Medicina e Odontologia, as taxas simuladas giraram em torno do elevado nível de $14 \%$ das vagas, ao passo que em carreiras menos valorizadas, como Enfermagem e Veterinária, estiveram por volta de apenas $4 \%$. Por ora apenas registremos esses resultados, pois mais tarde voltaremos a eles e a outros, análogos.

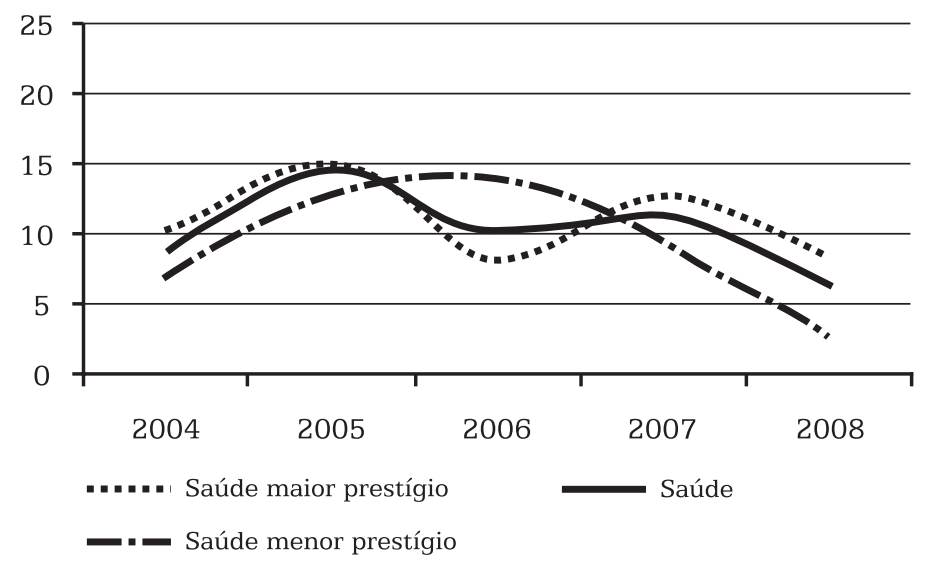

Gráfico 1.c - Saúde: simulações da aprovação de candidatos negros em cinco hipotéticos vestibulares da UnB, sem cotas, com o número de vagas real (\%)

Fonte: Microdados do Cespe/UnB; elaboração dos autores.

Já em 2007, em vez de sofrerem um acentuado aumento, conforme constatado nas outras duas áreas, as chances de entrada na Saúde subiriam apenas um ponto percentual, situando-se em $11 \%$. Nesse ano restabeleceu-se o padrão de menores probabilidades de acesso em cursos mais valorizados, que se manteria também no último ano do período. Neste, a área da Saúde acompanhou o padrão das demais áreas, pois as chances de ingresso cairiam muito, para 6\%, lideradas pela Medicina, curso no qual nenhum candidato negro seria aprovado em 2008 sem o sistema de cotas.

Simulações com vagas originais: interrogações sobre as variações das chances

Na seção anterior, os dados das simulações mostraram, em cada área do conhecimento, expressivas diferenças nas chances de ingresso de candidatos negros ao longo do quinquênio. No entanto, maiores que essas diferenças foram as variações nas chances de entrada em diversas carreiras específicas. Vejamos ilustrações destas variações. 
Nas Humanidades, no grupo de maior prestígio, as taxas simuladas de aprovação para candidatos negros na Arquitetura foram nulas em 2004, em 2006 e, também, em 2008, mas esses candidatos ocupariam 17\% das vagas do curso em 2005 caso o sistema de cotas inexistisse. Em Ciência Política, carreira do mesmo grupo, as oscilações nas chances de entrada também foram intensas: 25\% dos aprovados em 2005 seriam negros, mas em 2007 e em 2008 eles seriam apenas 5\% e 3\%, respectivamente. Já em Serviço Social, do grupo de cursos de menor prestígio, mesmo se inexistisse o sistema de cotas, $20 \%$ das vagas seriam ocupadas por candidatos negros em 2004 e, também, em 2008 - ano das mais baixas taxas de aprovação simuladas em praticamente todos os cursos -, mas as chances de ingresso desses candidatos seriam de apenas $13 \%$ em 2006.

Na área de Ciências também houve amplas variações em diversos cursos. O caso mais eloquente é certamente o de Engenharia Mecatrônica, carreira de elevado prestígio na qual nenhum negro ingressaria sem as cotas em 2006, mas em 2007, caso inexistissem as cotas, mais de 20\% dos aprovados nela seriam negros. Já no caso de Ciência da Computação, do mesmo grupo de cursos, ao contrário do padrão da maioria das carreiras, o pior ano de chances para candidatos negros foi 2007 (3\% de chances de entrada) e os melhores foram os de 2004 e 2005 (13\%). No grupo das carreiras menos valorizadas das Ciências, mais de $20 \%$ das vagas da Geologia seriam ocupadas por candidatos negros em 2005, mesmo se inexistissem as cotas; por outro lado, o pior ano de chances para candidatos negros a esse curso foi 2007, com probabilidade nula de aprovação, neste caso coincidindo com Ciência da Computação, do grupo de cursos de maior prestígio.

Na área da Saúde as variações tiveram igualmente apreciável amplitude. Em Medicina as taxas simuladas caíram de 14\% em 2006 para somente $6 \%$ no ano subsequente, chegando a ser nulas em 2008; na Odontologia, naqueles dois anos, elas sofreram uma diminuição menor, todavia ponderável, de 15\% para $10 \%$, e, em 2008, também foram nulas. No outro extremo do espectro do prestígio social, os índices na Enfermagem eram superiores a 20\% em 2004, desabavam para $4 \%$ em 2006, subiam para $18 \%$ no ano seguinte e despencavam para $7 \%$ em 2008.

Na seção anterior tratamos de hipóteses para explicar o movimento maior das taxas simuladas ao longo do quinquênio, considerando grupos de cursos e áreas do conhecimento. Discutimos uma hipótese para explicar o substancial aumento nas taxas de 2004 para 2005 em todos os grupos e áreas, para a qual se encontrou alguma evidência empírica, ainda que limitada. Levantamos uma outra hipótese quanto à queda nas taxas de 2007 para 2008, baseada na mudança dos procedimentos para a homologação da inscrição de cotistas, embora para tal hipótese não tenhamos alguma evidência adicional. As origens do movimento ascendente dos índices entre 2006 e 2007 não chegaram a ser discutidas e ainda aguardam estudos ulteriores. Ainda que muito falte para uma 
compreensão adequada das grandes tendências observadas, algo foi possível avançar nesse sentido.

Mas ainda não foi possível lidar de forma satisfatória com as grandes disparidades nas chances de ingresso em carreiras específicas em certos períodos de tempo. Considere-se que não há diferenças nos tipos de provas a que se submetem os candidatos: em cada vestibular, todos os candidatos fazem exatamente as mesmas provas, estejam eles inscritos no sistema universal ou no sistema de reserva de vagas. A única diferença se situa na prova de língua estrangeira, pois é o candidato quem escolhe o idioma em que fará esse exame. Nas demais provas, há diferenças na ponderação dos escores entre áreas, mas não numa mesma área; os resultados obtidos no exame de Linguagens, Códigos e Ciências Sociais recebem peso maior no caso dos candidatos a cursos das Humanidades, ao passo que para candidatos a carreiras das Ciências e da Saúde a maior ponderação é atribuída ao exame de Ciências da Natureza e Matemática. Nesse cenário, é bem possível que flutuações aleatórias no nível de preparo para o vestibular de candidatos que se inscreveram no sistema universal ou no de cotas, para este ou aquele curso, num ou noutro ano, possam desempenhar um papel relevante na explicação dos casos que fogem do comportamento típico de seu grupo de cursos, tal como na maioria das situações ilustrativas antes mencionadas.

\section{Um padrão no quinquênio: a demanda e as cotas}

Os dados para o quinquênio, em cada área, indicaram uma boa estabilidade da diferença nas chances de ingresso entre os grupos de cursos. Os índices simulados de aprovação de negros geralmente foram maiores nos grupos de cursos menos valorizados. Essa tendência decorre da autosseleção que ocorre antes do vestibular, que associa aspirações dos indivíduos a uma avaliação das probabilidades de ingresso na universidade, conforme anotou Queiroz (2004) ao examinar candidatos negros e brancos da UFBA, e é ela que faz convergir a demanda de candidatos negros para as carreiras de menor prestígio na UnB. De modo análogo, porém na direção oposta, os candidatos do sistema universal geralmente têm menor interesse pelos cursos menos valorizados. Entre estes candidatos, as avaliações de que suas chances de aprovação são mais elevadas que a dos negros, devido, por exemplo, à sua extração social mais elevada (e ao melhor preparo para o vestibular que geralmente a ela se associa), tendem a dirigir sua demanda para carreiras mais valorizadas, afastando-se de cursos da parte inferior da escala de prestígio. Ao se distanciarem desses cursos, neles aumentam as chances simuladas de ingresso dos negros.

Essa tendência é claramente perceptível no Gráfico 2, no qual apresentamos um indicador da demanda por parte de candidatos ao universal e as chances de ingresso de candidatos negros nos cursos de maior e menor prestígio de cada área. 


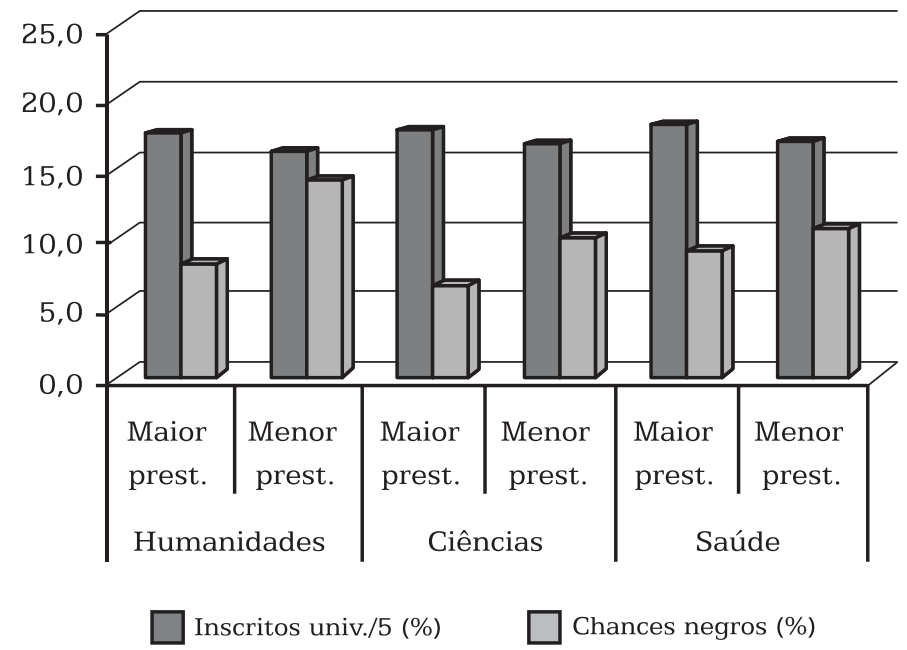

\section{Gráfico 2 - Candidatos do sistema universal e chances de aprovação de negros, por grupo de cursos nas áreas do conhecimento, médias 2004-2008 (\%)}

Fonte: Microdados do Cespe/UnB, elaboração dos autores.

No quinquênio, o leque de cursos oferecidos variou pouco em cada grupo, e o número de vagas não se ampliou de modo expressivo; assim, um indicador satisfatório da demanda por vagas por parte dos candidatos do sistema universal é a proporção de inscritos neste sistema. Na construção do Gráfico 2, tomamos a média dessa variável no quinquênio em cada grupo de cursos e a dividimos por uma constante (cinco), a fim de tornar sua magnitude aproximadamente comparável à das chances de ingresso de candidatos negros. Para estas chances, tomamos igualmente a média dos cinco anos em cada grupo de carreiras.

Nas Humanidades, como podemos observar no Gráfico 2, a média das proporções de candidatos inscritos no universal (média das demandas) diminui dos cursos mais valorizados para os menos concorridos, enquanto as médias das chances de aprovação de candidatos negros percorrem a rota oposta, crescendo dos cursos de maior prestígio (8\%) para os de prestígio menor (14\%). Nas carreiras da área de Ciências podemos constatar um padrão semelhante. Nos cursos da Saúde a diferença nas chances de ingresso de candidatos negros também é perceptível, embora de menor amplitude que nas outras áreas. Essa menor amplitude provavelmente decorre de uma autosseleção de candidatos negros mais intensa na Saúde que nas outras áreas, conforme constatou Velloso (2009) quando tratou de diferenças no rendimento de alunos cotistas e não cotistas na UnB.

Simulações com vagas originais e o rendimento na universidade

À vista dos resultados que obtivemos nas simulações, cabe indagar se as chances de ingresso dos candidatos negros, bem inferiores às dos 
inscritos no sistema universal, se refletiriam no rendimento dos alunos que entraram na UnB pela reserva de vagas. A pergunta é muito pertinente, pois uma das críticas ao sistema de cotas é a de que a admissão de candidatos com inferior desempenho no vestibular promoveria uma queda na qualidade do ensino na universidade. Num estudo de Velloso (2009) foram efetuadas comparações do rendimento na UnB para cada carreira no interior de cada grupo de cursos das áreas do conhecimento, referentes a três turmas de alunos que ingressaram nos processos seletivos de 2004, 2005 e 2006, antes discutidos. Quando a diferença entre as médias das notas dos dois segmentos, cotistas e não cotistas, era superior a 5\% num curso, foi considerado que existia uma diferença expressiva no rendimento; caso contrário, a diferença era tida como inexpressiva.

Nas Humanidades, no conjunto das três turmas, os dados não foram desfavoráveis aos cotistas, ainda que nas carreiras mais valorizadas a tendência tenha sido de notas maiores para os alunos que entraram pelo vestibular universal. Consideradas as diferenças expressivas entre as médias, favoráveis aos cotistas, junto com as diferenças inexpressivas, a soma dessas diferenças em cada um dos anos do triênio analisado situou-se em torno de $70 \%$ do total. Portanto, não se evidenciou uma superioridade de rendimento dos não cotistas, embora assim previssem os críticos do sistema de cotas. Em outras universidades, em cursos da área das Humanidades, foram encontrados resultados parecidos, como mostraram os dados de Brandão e Matta (2007) para a Universidade do Norte Fluminense ou os de Queiroz e Santos (2006) para a UFBA.

Em vários cursos da área, a semelhança de médias das notas de cotistas e não cotistas e, mais ainda, a superioridade das médias daqueles não se coadunariam com as menores chances de ingresso dos candidatos negros, supondo-se que o resultado do vestibular fosse um satisfatório preditor do rendimento no curso. A hipótese aventada para o aparente paradoxo foi a de que boa parte dos alunos que concorreram pelas cotas, valorizando a aprovação na universidade à qual não teriam acesso sem a reserva de vagas, tivesse se empenhado mais a fundo nos estudos e buscado vencer lacunas da formação anterior. A hipótese encontrou sustentação em pesquisas junto a alunos cotistas da UnB; nestas, foi constatado que os estudantes cotistas geralmente atribuíam grande importância à vaga conquistada na universidade, o que aumentava sobremodo sua autoestima (Ferreira, 2009; Holanda, 2008), um relevante fator para a dedicação ao estudo e o subsequente bom rendimento. ${ }^{2}$ Mais tarde, o estudo de Francis e Tannuri-Pianto (2010) constatou que de fato os cotistas estudavam significativamente mais que os não cotistas.

$\mathrm{Na}$ área de Ciências, na primeira das três turmas estudadas, os dados não se revelaram tão favoráveis aos cotistas quanto na área de Humanidades. A soma dos casos em que as médias dos cotistas foram expressivamente maiores, com os casos de diferenças insignificantes entre as médias, foi inferior de aproximadamente um terço do total em 2004, mas em cada um dos dois anos seguintes a soma oscilou em torno de
${ }^{2}$ A valorização da vaga conquistada certamente influi nas chances de evasão, que de fato se revelaram menores entre estudantes cotistas do que entre alunos que ingressaram pelo sistema universal, conforme apuraram Velloso e Cardoso (2008). 
70\%. Considerando esses dois últimos anos entre os três analisados, não se poderia afirmar que os alunos do vestibular universal tiveram rendimento sistematicamente superior aos cotistas, ainda que essa tendência estivesse presente nas carreiras socialmente mais valorizadas. Boa parte dos casos em que os cotistas tiveram rendimento superior no curso ou ombrearam suas notas com as dos outros colegas provavelmente poderia ser atribuída à maior dedicação aos estudos, com origem na valorização da vaga e na autoestima a ela associada.

Na área da Saúde, a soma dos resultados favoráveis aos cotistas com as diferenças nulas ou diminutas correspondeu a frações por volta de $70 \%$ do total em cada um dos anos do triênio. Esses resultados - que incluem a carreira mais competitiva do vestibular, a de Medicina - surpreendentemente são mais favoráveis aos cotistas que os resultados das Ciências; a explicação conecta-se à autosseleção anteriormente referida. Os dados de Velloso (2009) sugeriram que a autosseleção dos candidatos na Saúde, sendo geralmente mais intenso que nas Ciências, cuidaria então de melhor peneirar os cotistas, que, por esse processo, se aproximariam mais dos não cotistas em matéria de preparo para estudos universitários, tal como avaliado pelo vestibular. Um maior empenho nos estudos por parte de muitos alunos que concorreram pela reserva de vagas teria contribuído no mesmo sentido.

Em suma, no conjunto dos dados de um triênio, as menores chances de ingresso dos alunos aprovados pela reserva de vagas geralmente não conduziram a níveis inferiores de rendimento nos estudos realizados na UnB.

Um outro estudo sobre o rendimento de alunos da UnB, mais recente, apontou na mesma direção. Usando dados para os estudantes matriculados em 2007, o trabalho de Francis e Tannuri-Pianto (2010) valeu-se de uma análise de regressão múltipla do rendimento, tendo como variáveis explicativas a cor da pele/raça e características socioeconômicas, entre outras. A pesquisa encontrou um coeficiente negativo e significativo para pardos (mas não para pretos) no valor de 0,10, ou seja, a média do rendimento dos alunos pardos era apenas um décimo de pontos menor que a de seus colegas brancos (numa escala de 0 a 5). A diferença - denominada marginal pelos autores -, embora estatisticamente significativa, não chegava a ser expressiva. Em nossos dados, a média das notas do conjunto dos estudantes universal na UnB variou de 3,4 a 3,7 pontos entre 2004 e 2005; aplicando o resultado dos autores a nossos dados, constatamos que a diferença de 0,01 ponto correspondia a $3 \%$ ou menos da média das notas dos não cotistas.

\section{Simulações com vagas dobradas}

Teses contrárias à reserva de vagas, seja para negros, seja para egressos da escola pública, ou para ambos, postulam que o caminho para enfrentar as desigualdades raciais (e sociais) de acesso à educação superior residiria em políticas universalistas voltadas para a educação básica, como arguem Fry e Maggie (2005), por exemplo. Outras teses entendem que a 
alternativa adequada seria uma forte ampliação das vagas da universidade, assim aumentando as oportunidades de ingresso. Outras mais conjugam ambas as estratégias. Os pressupostos do primeiro desses argumentos sem dúvida têm fundamento, pois aquelas desigualdades vêm de muito antes das tentativas de entrada no ensino superior. As cotas para negros (ou para egressos da escola pública) nada mais são do que uma pequena correção de desigualdades raciais (e sociais) muito anteriores à busca pela universidade; os jovens que concluíram o ensino médio já passaram pela principal peneira escolar, a da seletividade racial e social, a da progressão ao longo da educação básica. Apesar de sua função marginal na correção dessas desigualdades, as cotas cumprem papel indispensável no alargamento das chances daqueles que, sem a reserva de vagas, não ingressariam na universidade.

Mas uma alentada ampliação das vagas na educação superior, conforme a segunda das teses referidas, teria efeitos realmente expressivos sobre as desigualdades raciais de acesso a esse nível de ensino? No intuito de avaliar a sustentação da tese com dados empíricos, realizaram-se outras simulações, com procedimentos análogos aos adotados nas anteriores, mas duplicando as vagas ofertadas.

Os resultados da simulação para 2004 trouxeram resultados inusitados. Se as vagas fossem duplicadas naquele vestibular, e inexistissem as cotas, somente $10 \%$ dos candidatos aprovados seriam negros (Tabela A-3 do Apêndice). Esse índice de aprovação para a universidade como um todo, na hipótese do dobro de vagas, é praticamente igual ao encontrado na simulação anterior (9\%), que considerou o número de vagas real (Tabela A-2 do Apêndice), dele diferindo por apenas pouco mais de um ponto percentual. Os dados de 2004 para o conjunto da UnB, portanto, não sustentam a tese de que um forte aumento nas vagas da educação superior reduziria as desigualdades raciais de acesso a esse nível de ensino.

A Tabela 1 apresenta, para candidatos negros, as diferenças entre duas taxas simuladas: as taxas calculadas com as vagas efetivamente ofertadas em cada curso, em cada ano, e as taxas calculadas com o número de vagas duplicadas, nos mesmos anos e cursos. Em 2004, as novas taxas (simulação com o dobro das vagas) nos grupos de cursos das três áreas do conhecimento em geral pouco divergiram dos índices obtidos com as vagas reais. Assim as diferenças entre elas variaram muito pouco, de meio ponto percentual a quase três pontos.

Resultados muito parecidos aos da UnB foram encontrados na Universidade Federal de Santa Catarina (UFSC), em um estudo de Tragtenberg et al. (2006). Investigando o impacto da adoção de propostas para aumentar a proporção de negros na universidade, os autores informam que, naquela instituição, na qual até então inexistia a reserva de vagas para negros, estes correspondiam a 9\% dos inscritos no vestibular de 2004 e, entre aprovados, a estimados $6 \%$. Nas simulações realizadas para mais de uma dezena de cursos, os resultados para a hipótese da UFSC oferecer o 
dobro de vagas foram comparados aos índices reais de aprovação de negros no vestibular de 2004. Na maioria dos cursos, foram muito pequenas as diferenças entre os índices reais de aprovação e os simulados, tal como ocorreu nas simulações para a UnB. À vista dos resultados para a UFSC, os autores concluíram que a duplicação do número de vagas não modificava as chances de ingresso de candidatos negros naquela universidade, aduzindo, sem dúvida com razão, que "isso contraria fortemente a tese de que um crescimento de vagas no ensino superior público levaria de forma automática à igualdade racial" (Tragtenberg et al., 2006, p. 488).

Tabela 1 - Diferenças entre as taxas de aprovação (simuladas) de candidatos negros em vestibulares da UnB: taxas com número de vagas real e taxas com número de vagas duplicado, 2004-2008 (pontos percentuais)

\begin{tabular}{|c|c|c|c|c|c|c|}
\hline \multirow{2}{*}{ Áreas } & \multirow{2}{*}{ Grupos de cursos } & \multicolumn{5}{|c|}{ Ano do vestibular } \\
\hline & & 2004 & 2005 & 2006 & 2007 & 2008 \\
\hline \multirow{3}{*}{ Humanidades } & Maior prestígio & 0,5 & 0,1 & 1,4 & 2,4 & 0,5 \\
\hline & Menor prestígio & 2,3 & 0,2 & 0,4 & 0,2 & 2,7 \\
\hline & Subtotal & 1,4 & 0,0 & 0,6 & 1,1 & 1,9 \\
\hline \multirow{3}{*}{ Ciências } & Maior prestígio & 0,7 & 1,4 & 1,4 & 2,1 & 1,6 \\
\hline & Menor prestígio & 2,9 & 1,5 & 4,0 & 1,7 & 2,6 \\
\hline & Subtotal & 1,9 & 1,5 & 2,8 & 1,9 & 2,7 \\
\hline \multirow{3}{*}{ Saúde } & Maior prestígio & 1,2 & 1,7 & $-2,3$ & $-1,2$ & 0,6 \\
\hline & Menor prestígio & $-0,6$ & 0,0 & 2,5 & 5,6 & $-0,6$ \\
\hline & Subtotal & 0,0 & 0,6 & 0,8 & 3,3 & $-0,2$ \\
\hline Total & UnB & 1,4 & 0,5 & 1,3 & 1,6 & 1,6 \\
\hline
\end{tabular}

Fonte: Microdados do Cespe/UnB, elaboração dos autores.

Retornemos às simulações na UnB com vagas hipoteticamente duplicadas. Nos anos subsequentes a 2004, a ordem de grandeza das diferenças entre os índices com vagas reais e os índices com vagas duplicadas não foram muito diversos dos registrados naquele ano. As duas únicas exceções foram as dos cursos de menor prestígio das Ciências em 2006, quando o índice com vagas dobradas foi quatro pontos percentuais maior, e a das carreiras menos concorridas da Saúde em 2007, quando a taxa para vagas dobradas foi seis pontos percentuais superior; em ambos os casos, uma diferença pequena. Registremos ainda que na área da Saúde, em alguns casos, a duplicação das vagas traria perdas aos candidatos negros - ainda que também pequenas. Nos cursos de menor prestígio dessa área em 2004 e em 2008, assim como nos cursos mais valorizados em 2006 e em 2007, se as vagas fossem duplicadas, os candidatos negros teriam chances de entrada ligeiramente menores que com as vagas originais.

A evidência para a UnB, à vista das taxas simuladas para o quinquênio, e a evidência para a UFSC testemunham contra a tese de que uma forte (mesmo fortíssima) ampliação de vagas na educação superior em substituição às cotas seria o mecanismo acertado para a diminuição das desigualdades sociorraciais de acesso do negro à universidade. 


\section{Nota final}

No presente estudo foram efetuadas simulações das chances de ingresso de candidatos negros na UnB em processos seletivos no quinquênio 2004-2008. Os dados foram apurados em cada uma das três áreas do conhecimento do vestibular (Humanidades, Ciências e Saúde) e, no interior de cada, por grupos de cursos conforme seu prestígio social (maior e menor prestígio). Desejávamos saber quais seriam as chances de ingresso de candidatos negros na UnB caso a reserva de vagas inexistisse. Inicialmente consideramos o número de vagas efetivamente disponível na seleção de cada ano. Nessas simulações, constatamos que, na maioria dos casos (grupos de cursos/áreas/anos), as cotas dobrariam - ou mais que dobrariam - as probabilidades de ingresso de candidatos negros e que seus efeitos positivos em geral seriam maiores nos cursos socialmente mais valorizados. Nessas situações, majoritárias, as cotas se revelaram uma poderosa alavanca para ampliar as chances de ingresso de jovens negros na UnB. Noutros casos, minoritários, a reserva de vagas ainda teria efeitos positivos, porém frequentemente eles seriam bem mais reduzidos.

Posteriormente adotou-se a suposição de que o quantitativo das vagas oferecidas pela universidade em cada vestibular seria instantaneamente duplicado. Ambos os tipos de simulação apresentaram resultados muito parecidos. Se as vagas fossem instantaneamente duplicadas, as chances de ingresso de candidatos negros se manteriam em patamares semelhantes aos alcançados com o número real de vagas ou, em alguns casos, sofreriam diminutas alterações. Esses resultados foram convergentes com os de outra universidade federal.

As simulações efetuadas na UnB e noutra universidade federal, se puderem ser generalizadas para o cenário da educação superior no País, parecem depor a favor das cotas e, ao mesmo tempo, ajudam a colocá-las em perspectiva. Em virtude das desigualdades sociais e raciais de acesso a um ensino de qualidade na educação básica, o número de negros com efetivas condições de ingresso na educação superior é pequeno comparativamente ao de não negros, mantidos os habituais critérios de seleção. Nesse contexto, não espanta que uma radical duplicação de vagas - ainda que só hipotética, porque inviável em curto ou médio prazo - não corresponda a uma igualmente drástica ampliação das probabilidades de ingresso de negros na universidade.

Os certificados de conclusão do ensino médio obtidos pelos jovens negros, formalmente idênticos aos dos brancos, escondem experiências educacionais qualitativamente muito diversas. Assim, do contingente de candidatos negros, apenas uma pequena parcela tem boas chances de ingresso na educação superior. Além disso, a qualidade da formação de cada jovem que se candidata a uma universidade é um evento passado, resultante de condições sociais e educacionais pregressas. Logo, a distribuição dessa qualidade entre negros e brancos independe do número de vagas disponíveis na educação superior pública e, portanto, não se altera expressivamente com uma ampliação das vagas. 
A evidência obtida contribui para situar as cotas em sua perspectiva, que tem dois lados: primeiro, o de que a reserva de vagas consiste num ajuste marginal, ainda que necessário, de desigualdades sociais e raciais pregressas; segundo, o de que é indispensável democratizar efetivamente a educação básica pública, oferecendo um ensino de qualidade a todos os que, em virtude da cor da pele ou de sua extração social, não costumam a ela ter acesso.

\section{Referências bibliográficas}

BARBOSA, M. L. O. A qualidade da escola e as desigualdades raciais no Brasil. In: SOARES, S.; BELTRÃO, K.; BARBOSA, M. L.; FERRÃO, M. E. (Orgs.). Os mecanismos de discriminação racial nas escolas brasileiras. Rio de Janeiro: Ipea, 2005. p. 93-119.

BELTRÃO, K. I.; TEIXEIRA, M. P. Cor e gênero na seletividade das carreiras universitárias. In: SOARES, S. et al. (Orgs.). Os mecanismos de discriminação racial nas escolas brasileiras. Rio de Janeiro: Ipea, 2005. p. 143-193.

BEVILAQUA, C. B. A implantação do "Plano de Metas de Inclusão Racial e Social" na Universidade Federal do Paraná. Curitiba: Universidade Federal do Paraná, 2005. [Não publicado].

BONAMINO, Alícia; FRANCO, Francisco Creso J.; ALVES, Fátima. The color of educational inequalities. Paper presented at the conference "Research for Results in Education: a Global Conference on Education Research in Developing Countries", Praga, 2005.

BRAGA, M. M.; PEIXOTO, M. C. L.; BOGUTCHI, T. F. Tendências da demanda pelo ensino superior: estudo de caso da UFMG. Cadernos de Pesquisa, São Paulo, n. 113, p. 129-152, jul. 2001.

BRANDÃO, A. A.; MATTA, L. G. Avaliação da política de reserva de vagas na Universidade Estadual do Norte Fluminense: estudo dos alunos que ingressaram em 2003. In: BRANDÃO, A. A. (Org.). Cotas raciais no Brasil: a primeira avaliação. Rio de Janeiro: DP \& A, 2007. p. 49-80.

CARDOSO, C. B. Efeitos da política de cotas na Universidade de Brasília: uma análise do rendimento e da evasão. 2008. 133 f. Dissertação (Mestrado em Educação) - Universidade de Brasília (UnB), Brasília, 2008.

CARVALHO, J. J. Inclusão étnica e racial no Brasil: a questão das cotas no ensino superior. São Paulo: Attar, 2005. 
DIAS, T. F. S. et al. Cursos diurnos e noturnos: fatores de aprovação no vestibular da UFMG. Cadernos de Pesquisa, São Paulo, v. 38, n. 133, p. 127-146, jan./abr. 2008.

DIAZ, M. D. M. Efetividade no ensino superior brasileiro: aplicação de modelos multinível à análise dos resultados do Exame Nacional de Cursos. Economia, Campinas, v. 8, n. 1, p. 99-127, jan./abr. 2007.

FERREIRA, E. Identidade, raça e representação: narrativas de jovens que ingressaram na Universidade de Brasília pelo sistema de cotas raciais. 2009. 211 f. Tese (Doutorado em Educação) - Universidade de Brasília (UnB), Brasília, 2009.

FRANCIS, A.; TANNURI-PIANTO, M. Using Brazil's racial continuum to examine the short-term effects of affirmative action in higher education. 2010. Disponível em: <www.economics.smu.edu.sg/events/ Paper/AndrewFrancis.pdf $>$.

FRY, P.; MAGGIE, Y. Cotas raciais: construindo um país dividido? Econômica, Rio de Janeiro, v. 6, n. 1, p. 153-161, jun. 2004.

O debate que não houve: a reserva de vagas para negros nas universidades brasileiras. In: FRY, P. A persistência da raça: ensaios antropológicos sobre o Brasil e a África Austral. Rio de Janeiro: Civilização Brasileira, 2005. p. 301-320.

GUimARÃES, A. S. A. Acesso de negros às universidades públicas. Cadernos de Pesquisa, São Paulo, n. 118, p. 247-268, mar. 2003.

HASENBALG, C. O contexto das desigualdades sociais. In: SOUZA, J. (Org.). Multiculturalismo e racismo: uma comparação Brasil-Estados Unidos. Brasília: Paralelo 15, 1997. p. 63-68.

HOLANDA, M. A. G. Trajetória de vida de jovens cotistas da UnB no contexto das ações afirmativas. 2008. 161 f. Dissertação (Mestrado em Educação) - Universidade de Brasília (UnB), Brasília, 2008.

MAIO, Marcos Chor; SANTOS, Ricardo V. Política de cotas raciais, os "olhos da sociedade" e os usos da Antropologia: o caso do vestibular da Universidade de Brasília (UnB). Horizontes Antropológicos, [online], Porto Alegre, v. 11, n. 23, p. 181-214, jun. 2005. Disponível em: <http://www.scielo.br/scielo.php?script=sci_arttext\&pid =S0104-71832005000100011 >. Acesso em: 28 jul. 2011. 
MUNANGA, K. Políticas de ação afirmativa em benefício da população negra no Brasil: um ponto de vista em defesa de cotas. In: SILVA, Petronilha B. G.; SILVÉRIO, Valter. (Orgs.). Educação e ações afirmativas: entre a injustiça simbólica e a injustiça econômica. Brasília: Inep, 2003. p. 115-128. Disponível em: <www.acaoeducativa. org.br/downloads/educaacoes_afirmativas.pdf $>$.

OSÓRIO, R. G; SOARES, S. A geração de 80: um documentário estatístico sobre a produção das diferenças educacionais entre negros e brancos. In: SOARES, S. et al. (Orgs.). Os mecanismos de discriminação racial nas escolas brasileiras. Rio de Janeiro: Ipea, 2005. p. 21-92.

QUEIROZ, D. Universidade e desigualdade: brancos e negros no ensino superior. Brasília: Líber Livro, 2004.

QUEIROZ, Delcele M.; SANTOS, Jocélio T. Sistema de cotas: um debate - dos dados à manutenção de privilégios e de poder. Educação \& Sociedade, Campinas, v. 27, n. 96, p. 717-737, out. 2006. Disponível em: <http://www.scielo.br/scielo.php?script=sci issuetoc\&pid $=0101-733020060003 \& \operatorname{lng}=\mathrm{pt} \& \mathrm{nrm}=$ iso $>$.

SAMPAIO, H.; LIMONGI, F.; TORRES, H. Equidade e heterogeneidade no ensino superior brasileiro. Brasília: Inep, 2000.

SANTOS, R. E. Políticas de cotas raciais nas universidades brasileiras: o caso da Uerj. In: FERES JÚNIOR, J.; ZONINSEIN, J. (Orgs.). Ação afirmativa e universidade: experiências nacionais comparadas. Brasília: Ed. UnB, 2006. p. 110-135.

SILVA, N. V. Cor e pobreza no centenário da abolição. In: SILVA, N. V.; HASENBALG, C. Relações sociais no Brasil contemporâneo. Rio de Janeiro: Fundo Ed., 1992.

SILVA, Petronilha B. G. Negros na universidade e produção do conhecimento. In: SILVA, Petronilha B. G.; SILVÉRIO, Valter. (Orgs.). Educação e ações afirmativas: entre a injustiça simbólica e a injustiça econômica. Brasília: Inep, 2003. p. 43-54. Disponível em: Disponível em: <www.acaoeducativa.org.br/downloads/educaacoes_afirmativas. pdf $>$.

SOARES, J. F.; ALVES, M. T. G. Desigualdades raciais no sistema brasileiro de educação básica. Educação e Pesquisa, São Paulo, v. 29, n. 1, p. 147-165, 2003.

TRAGTENBERG, M. H. et al. Como aumentar a proporção de estudantes negros na universidade? Cadernos de Pesquisa, São Paulo, v. 36, n. 128, p.473-495, maio/ago. 2006. Disponível em: <http://www.scielo.br/ scielo.php?script $=$ sci_arttext\&pid $=$ S0100-15742006000200010\&lng $=$ pt\&nrm $=$ iso\&tlng $=p t>$. 
VALLE, I. R. et al. Seleção meritocrática versus desigualdades sociais: quem são os inscritos e os classificados nos vestibulares da UFSC (1998-2007)? Linhas Críticas, Brasília, v. 16, n. 31, p. 391-418, jul./dez. 2010 .

VELLOSO, J. Cotistas e não cotistas: rendimento de alunos da Universidade de Brasília. Cadernos de Pesquisa, São Paulo, v. 39, n. 137, p. 621-644, maio/ago. 2009.

VELLOSO, J.; CARDOSO, C. B. Evasão na educação superior: alunos cotistas e não cotistas na Universidade de Brasília In: REUNIÃO ANUAL DA ASSOCIAÇÃO NACIONAL DE PÓS-GRADUAÇÃO E PESQUISA EM EDUCAÇÃO (Anped), 32., 2008, Caxambu, MG. Anais eletrônicos.

Caxambu, MG: ANPED, 2008. 1 CD-ROM.

Jacques Velloso, doutor em Educação pela Stanford University, é professor emérito da Universidade de Brasília (UnB) e pesquisador colaborador da Faculdade de Educação dessa instituição.

jacques.velloso@terra.com.br

Claudete Batista Cardoso, mestre em Educação pela Universidade de Brasília (UnB), é analista em Ciência e Tecnologia e coordenadora do Programa Institucional de Bolsas de Iniciação à Docência (Pibid) da Coordenação de Aperfeiçoamento de Pessoal de Nível Superior (Capes).

claudete.cardoso@capes.gov.br

Recebido em 18 de maio de 2011.

Aprovado em 20 de julho de 2011. 


\section{APÊNDICE}

Tabela A-1 - Candidatos a vestibulares da UnB por sistema de ingresso, 2004-2005

\begin{tabular}{|l|r|r|r|r|r|}
\hline $\begin{array}{l}\text { Sistema de } \\
\text { ingresso }\end{array}$ & 2004 & 2005 & 2006 & 2007 & 2008 \\
\hline Universal & 21.013 & 19.197 & 17.752 & 16.957 & 19.192 \\
\hline Cotas & 3.886 & 3.882 & 1.860 & 3.407 & 2.412 \\
\hline Total & 24.899 & 23.079 & 19.612 & 20.364 & 21.604 \\
\hline
\end{tabular}

Fonte: Microdados do Cespe/UnB, elaboração dos autores

Tabela A-2 - Simulações da aprovação de candidatos negros em cinco hipotéticos vestibulares da UnB, sem reserva de vagas, com o número de vagas real (\%)

\begin{tabular}{|c|c|c|c|c|c|c|}
\hline \multirow{2}{*}{ Áreas } & \multirow{2}{*}{$\begin{array}{c}\text { Grupos } \\
\text { de cursos }\end{array}$} & \multicolumn{5}{|c|}{ Ano do vestibular } \\
\hline & & 2004 & 2005 & 2006 & 2007 & 2008 \\
\hline \multirow{3}{*}{ Humanidades } & Maior prestígio & 7,5 & 14,3 & 4,3 & 10,1 & 5,0 \\
\hline & Menor prestígio & 13,3 & 20,2 & 13,2 & 16,9 & 7,6 \\
\hline & Subtotal & 10,6 & 17,4 & 9,0 & 13,9 & 6,4 \\
\hline \multirow{3}{*}{ Ciências } & Maior prestígio & 4,8 & 11,4 & 5,2 & 7,9 & 3,8 \\
\hline & Menor prestígio & 6,4 & 15,5 & 7,9 & 14,6 & 6,1 \\
\hline & Subtotal & 5,7 & 13,6 & 6,6 & 11,5 & 5,0 \\
\hline \multirow{3}{*}{ Saúde } & Maior prestígio & 7,0 & 12,8 & 14,0 & 9,3 & 2,3 \\
\hline & Menor prestígio & 10,0 & 15,0 & 8,1 & 12,5 & 8,1 \\
\hline & Subtotal & 8,9 & 14,2 & 10,2 & 11,4 & 6,1 \\
\hline Total & UnB & 8,8 & 15,8 & 8,4 & 12,8 & 6,0 \\
\hline
\end{tabular}

Fonte: Microdados do Cespe/UnB, elaboração dos autores.

Tabela A-3 - Simulações da aprovação de candidatos negros em cinco hipotéticos vestibulares da UnB, sem reserva de vagas, com o número de vagas duplicado (\%)

\begin{tabular}{|c|c|c|c|c|c|c|}
\hline \multirow{2}{*}{ Áreas } & \multirow{2}{*}{$\begin{array}{c}\text { Grupos } \\
\text { de cursos }\end{array}$} & \multicolumn{5}{|c|}{ Ano do vestibular } \\
\hline & & 2004 & 2005 & 2006 & 2007 & 2008 \\
\hline \multirow{3}{*}{ Humanidades } & Maior prestígio & 8,0 & 14,4 & 5,7 & 12,5 & 5,5 \\
\hline & Menor prestígio & 15,6 & 20,5 & 13,5 & 17,1 & 10,4 \\
\hline & Subtotal & 11,9 & 17,4 & 9,6 & 15,0 & 8,3 \\
\hline \multirow{3}{*}{ Ciências } & Maior prestígio & 5,5 & 12,8 & 6,6 & 10,0 & 5,3 \\
\hline & Menor prestígio & 9,3 & 17,1 & 11,9 & 16,3 & 8,7 \\
\hline & Subtotal & 7,5 & 15,0 & 9,4 & 13,3 & 7,7 \\
\hline \multirow{3}{*}{ Saúde } & Maior prestígio & 8,1 & 14,5 & 11,6 & 8,1 & 2,9 \\
\hline & Menor prestígio & 9,4 & 15,0 & 10,6 & 18,1 & 7,5 \\
\hline & Subtotal & 8,9 & 14,8 & 11,0 & 14,6 & 5,9 \\
\hline Total & UnB & 10,2 & 16,3 & 9,7 & 14,4 & 7,5 \\
\hline
\end{tabular}

Fonte: Microdados do Cespe/UnB, elaboração dos autores. 